\title{
ANALISIS TINGKAT KEPUASAN PASIEN RUMAH SAKIT DENGAN METODA IMPORTANCE PERFORMANCE ANALYSIS DAN POTENTIAL GAIN IN CUSTOMER VALUE INDEX
}

\author{
Muhammad Ibnu Mastur ${ }^{1}$, Mahma Matahari \\ Jurusan Teknik Industri, Fakultas Teknologi Industri Universitas Islam Indonesia ${ }^{1,2)}$ \\ Kampus Terpadu Jl.Kaliurang Km.14,5, Sleman Yogyakarta \\ E-Mail : Mastur@uii.ac.id
}

\begin{abstract}
Problems on the quality of health services is not new. In contrast to the quality of goods and service quality is not so easy to determine but it can be felt. Therefore, It would need the regional public hospital in Yogyakarta to find out how the level of customer satisfaction that can be used as a measure to make improvements in order to obtain an increase in customer satisfaction. To determine the performance of the regional public hospital in Yogyakarta represented by the value of the level of satisfaction, while in the repair of the attributes necessary to know the expectations of customers who are represented by the value of the interest rate. All activities were carried out using the method of Importance Performance Analysis (IPA).

By 33 attributes asked to regional public hospital in Yogyakarta are outpatient. Based on the value PGCV and Cartesian diagram turns out there are 12 attributes that need to be improved from the 19 attributes that need improvement. The value of new satisfaction rate reached 3.4794 .279 while the value of the level of importance of the maximum value 5. This proves that the regional public hospital in Yogyakarta services is still far from what is expected by the customer, or in other words, the customer was not satisfied. Advice author the regional public hospital in Yogyakarta immediately make improvement to the attributes which has the highest priority for it, for example, attribute Sensitivity employees toward customer complaints (patient), the waiting room is neat and clean, patient acceptance faster and easier.
\end{abstract}

Keywords : Important Performance Analysis (IPA), Level of Satisfaction, Gain Potential In Customer Value (PGCV).

\section{PENDAHULUAN}

Perkembangan dunia ilmu pengetahuan dan teknologi saat ini menuntut rumah sakit sebagai industri jasa kesehatan untuk terus meningkatkan kualitas pelayanan agar bisa memberikan kepuasan kepada konsumennya, mengingat banyaknya persaingan yang harus dihadapi.

Kepuasan konsumen adalah kondisi perasaan seseorang dimana harapan mereka terhadap suatu produk atau jasa tertentu yang diterima. sesuai dengan harapan yang diinginkan. Jika kenyataan yang diperoleh konsumen tidak sesuai atau kurang dari harapannya, maka konsumen akan merasa kecewa atau tidak puas. Sejalan dengan keinginan RSUD Jogja untuk melakukan perbaikan yang berkesinambungan.
Kepuasan pelanggan (pasien) dipengaruhi oleh banyak faktor antara lain kualitas tempat pelayanan, kualitas system pelayanan, dan kualitas sumberdaya manuasia yang melakukan pelayanan. Pada RSUD Jogya masih terlihat dengan jelas banyaknya antrian pasien yg akan berobat, ruang tunggu yang kurang nyaman, prosedur pendaftaran pasien yang kurang di mengerti calon pasien.

Berdasarkan hal tersebut perlu dilakukan analisis terhadap kinerja rumah sakit dalam usaha memenuhi harapan konsumen sehingga konsumen memperoleh kepuasan. Dengan menganalisis tingkat kepentingan /harapan (importance) pasien dan kinerja (performance) pelayanan rumah sakit, sehingga dapat diketahui kesenjangan 
Tabel 1 Referensi Penelitian Terdahulu

\begin{tabular}{|c|c|c|c|c|}
\hline $\begin{array}{c}\text { Author \& } \\
\text { Tahun }\end{array}$ & Metode & Subyek & Obyek & Hasil \\
\hline $\begin{array}{c}\text { (Nusaputra et al, } \\
2014)\end{array}$ & $\begin{array}{c}\text { Servqual, IPA \& } \\
\text { PGCV }\end{array}$ & $\begin{array}{c}\text { Pelanggan } \\
\text { Bengkel Astra }\end{array}$ & $\begin{array}{c}\text { Bengkel Astra } \\
\text { office }\end{array}$ & $\begin{array}{c}\text { Masih adannya } \\
\text { keluhan dari } \\
\text { service advisor } \\
\text { dalam } \\
\text { mendapatkan } \\
\text { pelayanan }\end{array}$ \\
\hline $\begin{array}{l}\text { (Wicaksono et } \\
\text { al, 2014) }\end{array}$ & PGCV \& Entropy & $\begin{array}{l}\text { Pasien Rumah } \\
\text { Sakit }\end{array}$ & $\begin{array}{c}\text { Rumah Sakit } \\
\text { Waluyo }\end{array}$ & $\begin{array}{c}\text { Masih perlu } \\
\text { adannya } \\
\text { perbaikan pada } \\
\text { fasilitas yang } \\
\text { ada pada rumah } \\
\text { sakit yaitu } \\
\text { kamar mandi } \\
\text { keindahan } \\
\text { rumah sakit dan } \\
\text { peralatan } \\
\text { penunjang } \\
\text { medis }\end{array}$ \\
\hline
\end{tabular}

antara apa yang diharapkan dan apa yang didapat konsmen senhingga manajemen bisa merencanakan apa yng perlu dilakukan agar kepuasan pelanggan dapat dipenuhi. Penulis tertarik untuk melakukan penelitian untuk perbaikan kualitas pelayanan dirumah sakit ini dengan metoda Importance and Performance Analysis dan Potential Gain In Customer Index. Dengan menggunakan metode ini manajemen rumah sakit bisa mengetahui factor apa saja yang memerlukan perbaikan untuk meningkatkan kinerja perusahaan.

\section{TINJAUAN PUSTAKA}

RSUD Jogja merupakan rumah sakit yang bergerak dalam bidang kesehatan. Banyaknya persaingan antara rumah sakit yang terdapat di Yogyakarta, dalam hal memberikan pelayanan kepada pelanggan, maka diperlukan usaha peningkatan pelayanan agar pelanggan merasa puas atas pelayanan yang telah diberikan oleh rumah sakit.

\subsection{Konsep Jasa}

Menurut Kotler (1994), jasa adalah tindakan atau perbuatan yang ditawarkan

oleh suatu pihak kepada pihak yang lain yang bersifat tidak berwujud (Intangible) dan pelanggan tidak dapat memiliki produk tersebut. Adapun karakteristik utama yang membedakan produk jasa dengan produk barang menurut (Tjiptono, 1996), yaitu :

1. Intangible (tidak terwujud).

2. Inseparibility (tidak dapat dipisahkan).

3. Intangible (tidak terwujud).

4. Inseparibility (tidak dapat dipisahkan).

5. Variability (bervariasi).

6. Perishability (tidak tahan lama).

\subsection{Arti Kualitas}

Pengertian kualitas sangatlah luas dan para ahli memiliki pendapat yang berbeda satu dengan yang lain, tergantung dari prespektif yang mereka gunakan dalam mendefinisikan kualitas. Gaspersz (1997) menyatakan bahwa pada dasarnya kualitas yaitu keistimewaan produk. 


\subsection{Kualitas Pelayanan}

Menurut Kotler (1994), pelayanan dapat didefinisikan sebagai : "tingkat keunggulan yang diharapkan dan pengendalian atas tingkat keunggulan tersebut untuk memenuhi konsumen". Dari definisi diatas, kualitas pelayanan didefinisikan sebagai segala sesuatu yang memfokuskan pada usaha-usaha memenuhi kebutuhan dan keinginan pelanggan. Parasuraman, Zeithaml, dan Berry (1998) mendefinisikan lima dimensi pokok yang berkaitan dengan kualitas pelayanan yang diberikan oleh industri jasa antara lain :

1. Bukti Fisik (Tangible), Meliputi fasilitas fisik, perlengkapan, dan peralatan yang digunakan serta penampilan pegawainnya dan sarana komunikasi.

2. Kehandalan (Reliability), yaitu kemampuan suatu perusahaan untuk memberikan pelayanan sesuai yang dijanjikan secara akurat dan terpercaya.

3. Daya Tanggap (Responsiveness), yaitu suatu kemampuan untuk membantu dan memberikan pelayanan yang cepat dan tepat kepada pelanggan dengan penyampaian informasi yang jelas.

4. Jaminan (Assurance), yaitu pengetahuan, kesopan-santunan, dan kemampuan para karyawan perusahaan untuk menumbuhkan rasa percaya para pelanggan.

5. Empati (Empathy), meliputi kemudahan melakukan hubungan, komunikasi yang baik, perhatian pribadi dan memahami kebutuhan para pelanggan.

\subsection{Arti Kepuasan Pelanggan}

Definisi kepuasan menurut Kotler (1994), adalah :

"Tingkat perasaan seseorang setelah membandingkan antara kinerja yang dirasakan dengan harapannya yang diinginkan". Apabila kinerja dibawah harapan, maka pelanggan akan kecewa. Bila kinerja sesuai harapan, pelanggan akan puas, sedangkan bila kinerja melebihi harapan, pelanggan akan merasa sangat puas. Konsep kepuasan pelanggan menurut (Tjiptono, 1996) dapat ditunjukan pada gambar 1.

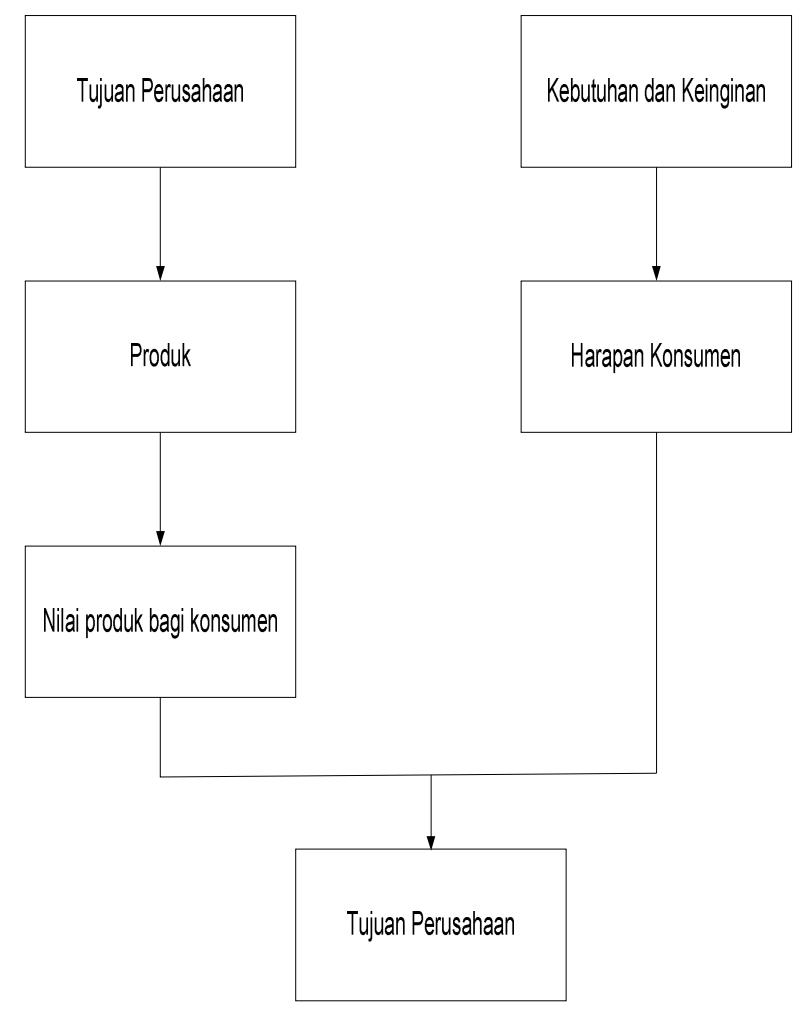

Gambar 1. Konsep Keputusan Konsumen.

Dalam memilih suatu pelayanan jasa, konsumen akan dipengaruhi oleh berbagai aspek. Menurut (Adikoesoemo, 1997) pada jasa pelayanan rumahsakit aspek - aspek yang berbengaruh terhadap kepuasan pelanggan antara lain adalah :

1. Karakteristik produk.

Meliputi pilihan jenis produk yang ditawarkan.

2. Harga.

Merupakan aspek penting, namun bukanlah yang terpenting dalam penentuan kepuasan (pelanggan) konsumen, biasannya semakin mahal harga maka konsumen mempunyai harapan yang lebih besar.

3. Pelayanan.

Misal keramahan dalam pelayanan akan menyenangkan konsumen. 
4. Lokasi

Salah satu aspek yang menentukan pertimbangan dalam memilih jasa pelayanan adalah faktor jarak.

5. Fasilitas.

Kelengkapan fasilitas terhadap kebutuhan jasa pelayanan mempunyai pengaruh terhadap kepuasan pelanggan.

6. Profil / Pandangan Menurut Konsumen. Penyedia jasa pelayanan harus selalu menjaga dan meningkat pandang (image) yang baik terhadap perusahaan.

7. Desain dan Tata Ruang.

Desaian dan tata rang yang enak dipandang akan sangat menyenangkan pelanggan.

8. Suasana Rumah Sakit.

Kepuasan konsumen akan dipengaruhi oleh suasana yang ada di perusahaan, missal keramahan dalam hubungan,tata ruang yang indah, situasi yang aman.

9. Komunikasi.

Dalam interaksi antara karyawan dan konsumen, maupun antar karyawan, perlu adannya konumikasi yang baik.

\subsection{Importance Performance Analysis} (IPA)

Konsep Importance Performance Analysis menurut (Supranto, 2001), sebenarnya berasal dari konsep Service Quality (SERVQUAL). Konsep ini menerjemahkan apa yang diinginkan konsumen diukur dalam kaitannya dengan apa yang harus dilakukan oleh perusahaan agar menghasilkan produk berkualitas, baik yang terwujud maupun yang tidak terwujud.

Bila konsep SERVQUAL hanya menganalisis tentang kesenjangan atau gap yang terjadi antara keinginan atau harapan dari konsumen dengan kinerja yang telah diberikan oleh produsen, pada konsep Importance Performance Analysis, dapat menganalisis tentang tingkat kepentingan dari suatu faktor yang mempengaruhi kepuasan pelanggan terhadap kinerja dari perusahaan.
Dengan demikian, perusahaan akan lebih terarah dalam melaksanakan strategi bisnisnya sesuai dengan prioritas kepentingan konsumen yang paling dominan.

Importance Performance Analysis (IPA) pertama kali diperkenalkan oleh Martilla dan James pada tahun 1997 dengan tujuan untuk mengukur kepuasan pelanggan terhadap suatu produk beserta pelayanannya.

\subsection{Tingkat Kesesuaian}

Dari hasil penilaian terhadap tingkat kepentingan dan tingkat kepuasan dapat dihitung besarnya tingkat kesesuaian. Tingkat kesesuaian adalah hasil perbandingan jumlah nilai kepuasan dengan jumlah nilai kepentingan. Tingkat kesesuaian inilah yang akan menentukan suatu atribut yang perlu untuk dilakukan perbaikan.

Nilai Tingkat Kesesuaian adalah :

$$
T k i=\frac{\Sigma X i}{\Sigma Y_{i}^{i}} \times 100 \%
$$

Dengan :

Tki $=$ Tingkat Kesesuaian.

$\sum \mathrm{Xi}=$ Jumlah nilai tingkat kepuasan pelanggan terhadap kinerja perusahaan.

$\sum \mathrm{Yi}=$ Jumlah nilai tingkat kepentingan pelanggan thd suatu faktor (atribut).

\subsection{Diagram Kartesius}

Dalam Importance Performance Analysis digunakan diagram kartesius yaitu suatu bidang datar yang dibagi menjadi empat bagian yang dibatasi oleh dua garis berpotongan tegak lurus dengan koordinat ( $\overline{\mathrm{X}}, \overline{\overline{\mathrm{Y}}}$ ) dimana $\overline{\mathrm{X}}$ merupakan rata - rata dari seluruh skor tingkat kepuasan dan $\overline{\mathrm{Y}}$ merupakan rata - rata dari seluruh skor tingkat kepentingan. 


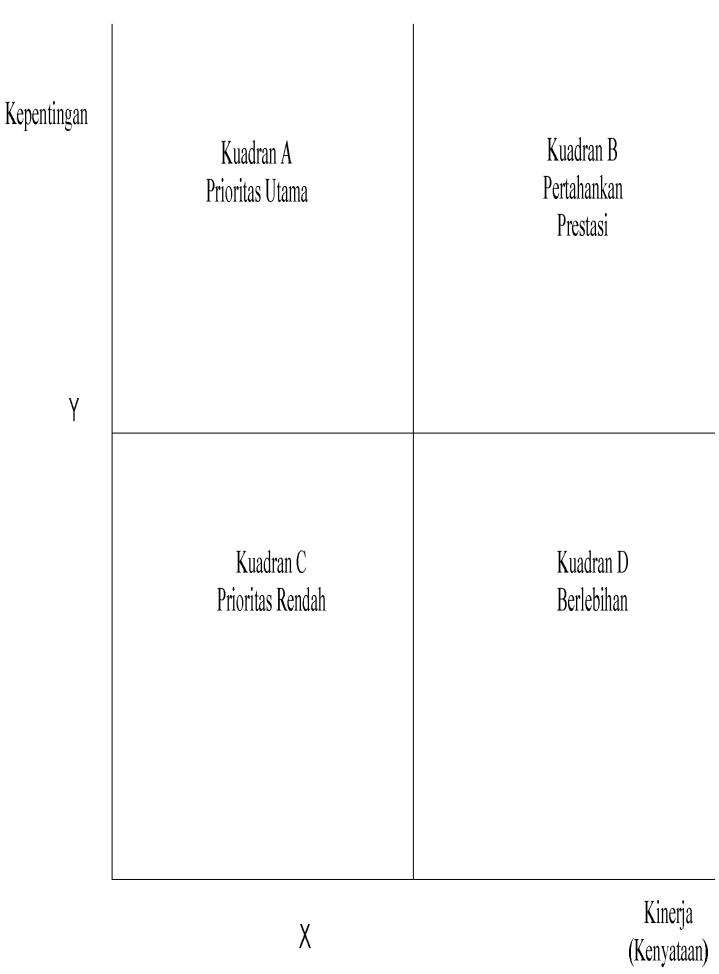

Gambar 2. Diagram Kartesius.

Empat kuadran yang ada pada diagram kartesius dipakai untuk menentukan posisi suatu faktor terhadap tingkat kepentingan dan tingkat kepuasan, sehingga kita bisa melakukan analisis terhadap faktor tersebut.

1. Kuadran I atau kuadran A.

Faktor - faktor yang berada pada kudran ini perlu diprioritaskan untuk diperbaiki, karena pada kuadran ini suatu faktor mempunyai tingkat kepentingan yang tinggi dengan tingkat kepuasan yang rendah.

2. Kuadran II atau kuadran B.

Faktor - faktor yang berada pada kuadran ini harus dipertahankan, karena faktor tersebut mempunyai tingkat kepentingan tinggi sedangkan tingkat kepuasan juga tinggi.

3. Kuadran III atau kuadran C.

Pada kuadran ini faktor mempunyai tingkat kepentingan yg rendah dan tingkat kepuasan juga rendah. Perlu ada pemilihan faktor yg perlu ada perbaikan.

4. Kuadran IV atau kuadran D.

Kuadran ini dikatagorikan sebagai daerah berlebihan, karena terdapat faktor yang bagi pelanggan tidak penting, akan tetapi pelanggan merasa sangat puas terhadap kinerja perusahaan.

Untuk menentukan posisi faktor (atribut) pada diagram kartesius perlu dihitung harga rata-rata dari tingkat kepentingan dan tingkat kepuasan dari hasil pengkuran dari responden yaitu :

$$
\begin{aligned}
& \bar{X}=\frac{\Sigma x i}{n} . \\
& \bar{Y}=\frac{\Sigma y i}{n} .
\end{aligned}
$$

Dengan :

$\bar{X}=$ Nilai rata - rata tingkat kepuasan.

$\bar{Y}=$ Nilai rata - rata tingkat kepentingan.

$\mathrm{n}=$ Jumlah responden.

Sedangkan untuk menentukan diagram kartesiusnya perlu dihitung harga rata-rata dari harga rata - rata untuk semua atribut yang berpengaruh terhadap tingkat kepuasan pelanggan, yaitu :

$$
\begin{aligned}
& \overline{\bar{X}}=\frac{\Sigma_{i}^{k} \bar{x}}{k} \\
& \overline{\bar{Y}}=\frac{\mathbf{\Sigma}_{i}^{k} \bar{y}}{\boldsymbol{k}} .
\end{aligned}
$$

Dimana :

$\overline{\bar{x}}=$ Nilai rata - rata tingkat kepuasan total.

$\overline{\bar{y}}=$ Nilai rata - rata tingkat kepentingan total.

$\mathrm{k}=$ Banyaknya faktor (atribut).

\subsection{Potential Gain In Customer Values (PGCV) \\ PGCV digunakan untuk melengkapi} hasil Importance and Performance Analysis yang akan dipakai untuk menentukan prioritas perbaikan yang harus dilakukan oleh perusahaan dengan menghitung harga dari :

\section{Achive Customer Value (ACV)}

ACV adalah hasil kali nilai rata tingkat kepuasan dengan nilai rata tingkat kepentingan dari hasil pengukuran. 
$\mathrm{ACV}=\bar{X} \times \bar{Y}$

2. Itimately Desire Customer Value (UDCV)

UDCV adalah hasil kali dari nilai tingkat kepuasan maksimum dengan nilai rata - rata tingkat kepentingan.

$$
\mathrm{UDCV}=\bar{Y} \times \max =. \bar{Y} \times
$$

Dimana :

$\bar{Y}=$ Skor rata - rata tingkat

kepentingan.

$\mathrm{Xmax}=$ Nilai tertinggi dari tingkat kepuasan yaitu 5 .

3. Indeks Potential Gain In Customer Values (PGCV)

PGCV adalah selisih antar UDCV dan ACV.

Nilai PGCV yang paling besar (maksimum) dipakai sebagai rujukan untuyk menentukan atribut yang menjadi prioritas utama untuk dilakukan perbaikan, kemudian nilai yang kedua dan seterusnya secara berurutan.

$$
P G C V=U D C V-A C V \text {. }
$$

\section{METODE PENELITIAN}

Pada bab ini memuat obyek penelitian, data yang digunakan dan tahapan yang telah dilakukan dalam penelitian secara ringkas dan jelas. Metode ini meliputi metode pengumpulan data, dan alat bantu analisis data.

\subsection{Obyek Penelitian}

Penelitian dilakukan diperusahaan yang bergerak dibidang kesehatan, yaitu di Rumah Sakit Umum Daerah Jogja. Pada penelitian ini, yang menjadi obyek penelitian adalah pasien rawat jalan RSUD Jogja.

\subsection{Identifikasi Masalah}

Dalam penelitian ini, dilakuakan identifikasi masalah yang ada pada rumah sakit dimana masih adannya ketidakpuasan pelanggan / pasien terhadap kinerja yang diberikan rumah sakit yang kemudian dianalisis dengan menggunakan metode Importance Performance Analysis (IPA), dan bagaimana prioritas perbaikan layanan yang diinginkan pasien dengan Tingkat Kesesuaian dan Potential Gain in Customer Value sehingga dapat menghasilkan strategi yang lebih berorientasi pada peningkatan kualitas pelayanan dan kepuasan konsumen.

\subsection{Pengumpulan dan Pengolahan Data 3.3.1. Penyusunan Kuesioner}

Kuesioner adalah alat untuk mengumpulkan data dengan cara mengajukan pertanyaan atau pernyataan yang diberikan oleh peneliti untuk dijawab oleh responden untuk membantu pembuatan kuesioner maka perlu dilakukan :

\section{a. Studi Pustaka}

Studi pustaka dilakukan untuk menambah wawasan tentang factor - faktor yang berkaitan dengan dimensi tangible (bukti fisik), assurance (jaminan), reability (kehandalan), responsiveness (daya tanggap), dan empathy (empati) yang berpengaruh terhadap tingkat kepuasan pelanggan.

b. Tinjauan Lapangan

Kegiatan dalam tinjauan lapangan antara lain melihat secara langsung faktor -faktor yang berhubungan dengan pelayanan pelanggan yang terdiri dari 5 dimensi

seperti yang ada pada kajian pustaka serta visi dan misi rumahsakit.

\subsubsection{Penentuan Ukuran Sampel}

Pada penelitian yang menggunakan kuesioner sebagai input, biasanya dilakukan uji kecukupan data untuk menentukan berapa banyak jumlah sampel yang digunakan. Penentuan sampel yang populasinya belum diketahui dapat menggunakan rumus sebagai berikut :

$$
\mathrm{n}=\mathrm{p}(1 \mathrm{p})\left[\frac{z \alpha / 2}{s E}\right]^{2}
$$

Dimana :

$\mathrm{N}=$ Ukuran sampel yang dibutuhkan.

$\mathrm{p}=$ Proporsi sebenarnya dari populasi. 
$\mathrm{SE} \quad=$ Sampling error (kesalahan sampling).

$Z_{\alpha / 2}=$ Nilai $\mathrm{z}$ distrbusi normal standar dari tingkat keyakinan.

\subsection{Pengolahan Data}

\subsubsection{Uji Validitas}

Kesahihan (validitas) adalah tingkat kemampuan suatu instrumen untuk mengungkapkan sesuatu yang menjadi sasaran pokok pengukuran yang dilakukan dengan instrumen tersebut (Hadi, 1991). Suatu angket / kuesioner dikatakan sahih (valid) jika pertanyaan pada suatu angket mampu untuk mengungkapkan sesuatu yang akan diukur oleh angket tersebut. Analisis kesahihan atribut bertujuan untuk menguji apakah tiap - tiap atribut pertanyaan telah mengungkapkan faktor yang ingin diselidiki sesuai dengan kondisi populasinya. Suatu atribut dikatakan sahih apabila korelasi atribut dengan faktor bernilai positif dan $r$ hitung $>\mathrm{r}$ tabel. Pengujian validitas item dalam penelitian ini dilakukan dengan menggunakan uji Korelasi.

\subsubsection{Uji Reliabilitas}

Uji ini digunakan untuk mengukur konsistensi jawaban atau tanggapan responden terhadap keseluruhan item pertanyaan yang diajukan. Hadi (1991), mengatakan bahwa uji reliabilitas digunakan untuk menunjukkan sejauh mana alat pengukur (instrumen) dapat memperlihatkan kemantapan atau stabilitas hasil pengamatan. Bila kita melakukan pengukuran dengan instrumen tersebut dalam waktu berikutnya dengan kondisi tetap ternyata hasilnya tidak mengalami perubahan. Keandalan berarti bahwa berapa kali pun atribut - atribut kuesioner ditanyakan kepada responden yang berlainan, hasilnya tidak akan menyimpang terlalu jauh dari rata - rata jawaban responden untuk atribut tersebut.

\subsubsection{Important Performance Analysis (IPA)}

Untuk menentukan atribut yg memerlukan perbaikan dengan menghitung nilai Tingkat kesesuaian dan diagram kartesius. Sedangkan untuk mengurutkan atribut-atribut yang perlu perbaikan dengan memperhatikan nilai PGCV. Nilai Tingkat Kesesuaian adalah :

$$
T k i=\frac{\Sigma X i}{\sum Y i} \times 100 \%
$$

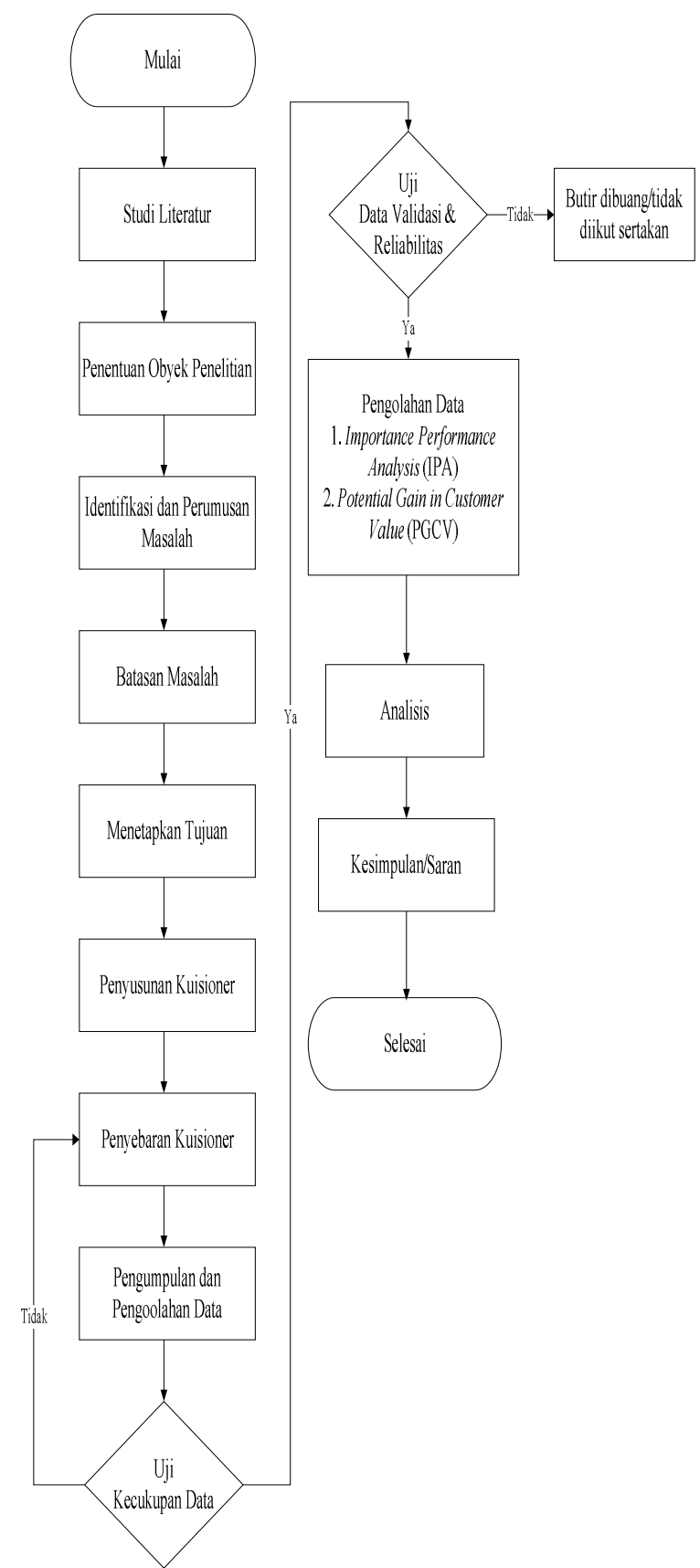

Gambar 3. Diagram Alir Penelitian. 
Tabel 2 Urutan Atribut - atribut Dalam Kuadran I yang Perlu Perbaikan.

\begin{tabular}{|c|c|c|c|c|c|c|}
\hline No & Atribut Kuisioner & Dimensi & TK & $\mathbf{A} / \mathbf{H}$ & $\bar{X}$ & $\bar{Y}$ \\
\hline 1 & $\begin{array}{l}\text { Ruang tunggu yang rapi dan } \\
\text { bersih }\end{array}$ & Tangibles & 77,56 & A & 3,36 & 4,33 \\
\hline 2 & $\begin{array}{l}\text { Ketepatan dan kecepatan dokter } \\
\text { dalam menetapkan diagnosa } \\
\text { penyakit }\end{array}$ & Asurrance & 78,10 & A & 3,41 & 4,37 \\
\hline 3 & $\begin{array}{l}\text { Ketersediaan pelayanan } \\
\text { penunjang medis yang lengkap }\end{array}$ & Asurrance & 78,57 & A & 3,46 & 4,40 \\
\hline 4 & Ruang periksa yang nyaman & Tangibles & 78,76 & A & 3,44 & 4,37 \\
\hline 5 & $\begin{array}{l}\text { Kebersihan, Keindahan dan } \\
\text { Kenyamanan Rumah Sakit }\end{array}$ & Tangibles & 80,13 & A & 3,46 & 4,31 \\
\hline 6 & $\begin{array}{l}\text { Karyawan selalu melakukan } 3 \mathrm{~S} \\
\text { (salam, senyum, sapa) }\end{array}$ & Empathy & 80,40 & A & 3,46 & 4,30 \\
\hline
\end{tabular}

\section{HASIL DAN PEMBAHASAN}

Berdasakan nilai Tingkat Kesesuaian, PGCV dan Diagram Kartesius, faktor faktor (atribut - atribut) yang berada pada kuadran I sangat perlu untuk dilakukan perbaikan. Perbaikan dimulai dari factor (atribut) yang memiliki nilai PGCV yg tertinggi, sedangkan untuk faktor - faktor yang berada pada kuadran III sebaiknya dipertimbangkan perbaikannya.

Berdasarkan nilai tingkat kesesuaian (TK) dan nilai PGCV ada 19 atribut yang Perlu perbaikan yaitu :

1. Kepekaan karyawan terhadap keluhan pelanggan.

2. Pelayanan pemeriksaan yang cepat dan tepat.

3. Penerimaan pasien dengan cepat dan mudah.

4. Ruang tunggu yang rapi dan bersih.

5. Kegiatan rumah sakit sesuai dengan jadual yang telah ditetapkan.

6. Kantin yang lengkap dan higienis.

7. Kecepatan dan ketepatan dokter dalam menetapkan diagnose penyakit.

8. Kemudahan pasien (pelanggan) $\mathrm{dlm}$ melaporkan pengaduan.

9. Ruang periksa yang nyaman.

10. Ketersediaan pelayanan penunjang medis yang lengkap.

11. Kemampuan dokter dan perawat untuk membuat pelanggan percaya terhadap perawatan.
12. Kebersihan, keindahan, dan kenyamanan rumah sakit.

13. Karyawan selalu melakukam $3 \mathrm{~S}$ (salam, senyum, sapa).

14. Alat pemeriksaan yang lengkap dan canggih.

15. Kesabaran karyawan dalam memberikan penjelasan kepada pelanggan.

16. Kedisiplinan petugas pelayanan.

17. Toilet yang bersih dan tidak berbau.

18. Apotek yang lengkap.

19.Tempat ibadah yang rapid an bersih.

Dari 19 atribut ini hanya atribut atribut yang berada pada kuadran I dan kuadran III diagram Kartesius yang menjadi prioritas untuk diperbaiki.

Atribut yang perlu perbaikan adalah atribut yang berada pada kuadran I dan kuadran III pada diagram Kartesius (gambar 2) yaitu : Kuadran I. Atribut - atribut yang masuk di kuadran I adalah atribut - atribut yang mempunyai tingkat kepentingan tingi sedangkan tingkat kepuasan yang rendah, oleh sebab itu atribut - atribut pada kuadran ini perlu adanya perbaikan untuk meningkatkan tingkat kepuasan pelanggan, dengan urutan perbaikan seperti pada tabel 2.

Pada kuadran ini III atribut mempunyai tingkat kepuasan yang rendah tetapi menurut pelanggan juga mempunyai tingkat kepentingan yang rendah, oleh sebab itu 
Tabel 3 Atribut - atribut Dalam Kuadran III

\begin{tabular}{|c|c|c|c|c|c|c|}
\hline No & Atribut Kuisioner & Dimensi & TK & $\mathbf{A} / \mathbf{H}$ & $\bar{X}$ & $\bar{Y}$ \\
\hline 1 & $\begin{array}{l}\text { Kemampuan dokter dan } \\
\text { perawat bisa membuat } \\
\text { pasien mempercayakan } \\
\text { sepenuhnya perawatan }\end{array}$ & Empathy & 78,46 & $\mathrm{~A}$ & 3,49 & 4,44 \\
\hline 2 & $\begin{array}{l}\text { Alat pemeriksaan yang } \\
\text { lengkap dan canggih }\end{array}$ & Tangibles & 78,85 & A & 3,51 & 4,46 \\
\hline 3 & $\begin{array}{l}\text { Toilet yang bersih dan tidak } \\
\text { berbau }\end{array}$ & Tangibles & 79,94 & A & 3,53 & 4,41 \\
\hline 4 & Apotek yang lengkap & Tangibles & 80,06 & A & 3,61 & 4,51 \\
\hline 5 & $\begin{array}{l}\text { Kedisiplinan petugas } \\
\text { pelayanan }\end{array}$ & Empathy & 81,06 & A & 3,49 & 4,30 \\
\hline 6 & $\begin{array}{l}\text { Tempat ibadah yang rapi } \\
\text { dan bersih }\end{array}$ & Tangibles & 81,29 & A & 3,60 & 4,43 \\
\hline 7 & $\begin{array}{l}\text { Area tempat parkir yang } \\
\text { luas dan aman }\end{array}$ & Tangibles & 81,33 & $\mathrm{H}$ & 3,49 & 4,29 \\
\hline 8 & Keadilan dalam pelayanan & Asurrance & 82,18 & $\mathrm{H}$ & 3,56 & 4,33 \\
\hline 9 & $\begin{array}{l}\text { Laboratorium yang lengkap } \\
\text { dan canggih }\end{array}$ & Tangibles & 82,24 & $\mathrm{H}$ & 3,57 & 4,34 \\
\hline 10 & $\begin{array}{l}\text { Memberikan kemudahan } \\
\text { mencari informasi yang } \\
\text { dibutuhkan pasien berkaitan } \\
\text { dengan rencana pengobatan }\end{array}$ & Tangibles & 83,00 & $\mathrm{H}$ & 3,56 & 4,29 \\
\hline 11 & Kerahasiaan data pasien & Asurrance & 86,80 & $\mathrm{H}$ & 3,76 & 4,33 \\
\hline
\end{tabular}

perlu dipilih mana atribut pada kuadran ini yang perlu diperbaiki berdasarkan nilai Tingkat Kesesuaian (Tk) dan nilai PGCV.

Atribut - atribut yang perlu diperbaiki adalah atribut yang mempunyai tingkat kesesuaian kurang dari 81,33\% (kode A), yang berada dalam kuadran I (yg utama), dan yang berada dalam kuadran III (perlu dipilih). Perbaikan yang dilakukan dengan memperhatikan apa yang telah dilakukan oleh pihak rumah sakit, sehingga hal - hal yang masih dirasa kurang bisa ditambahkan agar apa yang diharapkan pelanggan dapat tercapai, misalnya;

\subsection{Usulan Perbaikan Atribut - atribut Pada Kuadran I}

Atribut - atribut pada kuadran I perlu diperbaiki karena memiliki tingkat kepentingan yang tinggi sedangkan tingkat kepuasan pelanggan cukup rendah dengan urutan sebagai berikut :
1. Ruang Tunggu yang Bersih.

Atribut ini nilai tingkat kepuasan 3,36 yang masih jauh dari tingkat kepuasan maksimal yaitu 5 serta tingkat kesesuai 77,56 . Perbaikan yang diusulkan antara lain jadual pembersihan lebih dari sekali tiap hari, sehingga sebelum kotor sudah dibersihkan kembali.

2. Kecepatan dan Ketepatan Dokter Dalam Mendiagnosa Penyakit.

Nilai tingkat kepuasan hanya 3,41 dan tingkat kesesuaian 78,10, usulan perbaikannya peningkatan profesional dokter dengan training atau studi lanjut.

3. Ketersediaan Pelayanan Penunjang Medis yang Lengkap.

Nilai kepuasan 3,46 dan tingkat kesesuaian 78,57, usulan perbaikannya adalah perlu perencanaan kebutuhan peralatan penunjang medis berdasarkan pertumbuhan banyaknya pelanggan. 
4. Ruang Pemeriksaan yang Nyaman.

Nilai tingkat kepuasan 3,44 dan tingkat kesesuaian 78,76, usulan perbaikannya adalah perlu memperbaiki lay out ruang beserta desain interiornya.

5. Kebersihan, Keindahan, dan Kenyamanan Rumah Sakit.

Nilai tingkat kepuasan 3,46 dan tingkat kekesesuaian 80,13, usulan perbaikannya adalah perlunya penataan taman, ruangan, dan desain interior maupun eksterior.

6. Karyawan Selalu Melakukan 3S (Salam, Senyum, Sapa).

Nilai tingkat kepuasan 3,46 dan tingkat kesesuaian 80,40, usulan perbaikannya adalah secara rutin didakan training pembinaan sikap karyawan menghadapi pelanggan.

\subsection{Usulan Perbaikan Atribut - atribut Pada Kuadran III}

Atribut - atribut pada kuadran I yang perlu diperbaiki dengan urutan sebagai berikut :

1. Kemampuan dokter dan perawat untuk membuat pelanggan (pasien) percaya terhadap perawatan yang dialami. Usulan perbaikannya perlu diadakan kursus dan pelatihan bagi dokter dan perawat dalam bersikap, berbicara kepada pasien agar pasien yakin bahwa dokter dan perawat bisa menyembuhkan penyakitnya.

2. Alat pemeriksaan yang lengkap dan canggih.

3. Usulan perbaikannya perlu dipikirkan jenis alat dan dana yang dibutuhkan.

4. Toilet yang bersih dan tidak berbau. Usulan perbaikannya jadual pembersihan perlu ditambah dengan penambahan parfum.
5. Apotek yang lengkap. Perlu perencanaan kebutuhan obat yang sesuai banyaknya pertambahan pasien.

6. Kedisiplinan petugan pelayanan. Perlu SOP yang jelas dan pengawasan yang rutin.

7. Tempat ibadah yang rapi dan bersih. Jadwal pembersihan dan larangan tidur di musolla.

\section{KESIMPULAN}

Berdasarkan hasil pembahasan yang telah dilakukan maka hasil penelitian di RSUD Yogyakarta adalah :

1. Tingkat kepuasan pelangan baru mencapai angka 3,479 dan tingkat kepentingan 4,279 dari angka maksimal 5. Artinya masih cukup besar kesenjangan antara apa yang diharapan pelanggan dengan apa yang diterima oleh pelanggan, sehingga bisa dikatakan pelanggan merasa belum puas. Berdasarkan nilai PGCV dan diagram Kartesius ada 12 atribut yang sangat perlu untuk dilakukan perbaikan dari 19 atribut yang perlu perbaikan, antara lain Kepekaan karyawan terhadap keluhan pelanggan (pasien), Ruang tunggu yang rapi dan bersih, Penerimaan pasien yang cepat dan mudah.

2. Langkah - langkah yang perlu dilakukan yaitu dengan memperhatikan apa yang telah dilakukan dengan menambah inovasi - inovasi baru guna memperbaiki kinerja atribut - atribut yang memerlukan perbaikan. 


\section{DAFTAR PUSTAKA}

Adikoesoemo. Manajemen Rumah Sakit. Jakarta: Pustaka Sinar Harapan, 1997.

Gaspersz, V. Manajemen Kualitas dalam Industri Jasa. Jakarta: Gramedia Pustaka Utama, 1997.

Hadi, S. Analisis Butir Instrumen Angket, Tes dan Nilai Skala dengan BASICA. Yogyakarta: Andi Offset, 1991.

Kotler, P. Manajemen Pemasaran Jilid I Edisi Keenam. Jakarta: Erlangga, 1994.

Martilla, \& James. Importance-Performance Analysis. Journal of Marketing , 41,1317, 1997.

Nusaputra, N., Choiri, M., \& Wijaya Nata, L. T. Analisis peningkatan Kualitas Pelayanan Bengkel Dengan Metode SERVQUAL,IPA,PGCV, 2014.

Parasuraman, A., Zeithaml, \& Berry. Servqual : A Multiple-item Scale for Measuring Customer Perceptions for Service Quality. Journal of Retailing, 1998.

Supranto, J. Pengukuran Tingkat Kepuasan Pelanggan untuk Menaikkan Pangsa Pasar. Jakarta: PT Rineka Cipta, 2001.

Tjiptono, F. Manajemen Jasa. Yogyakarta: Andi Offset, 1996.

Wicaksono, B., Setyanto, N. W., \& Oke. Analisis Kepuasan Pelanggan pada Pelayanan Kesehatan dengan Menggunakan Metode PGCV dan Entropy (RS Mardi Waluyo), 2014. 